\title{
ON THE QUESTION OF THE INVESTIGATOR'S ALGORITHM OF ACTIONS DURING THE INTERROGATION OF FOREIGN NATIONALS INVOLVED IN CRIMINAL PROCEEDINGS AS VICTIMS
}

\begin{abstract}
Anna I. Zemskova
Volgograd Academy of the Ministry of Internal Affairs of the Russian Federation, Volgograd, Russian Federation

Introduction: the paper discusses some features of the techniques of interrogating foreign nationals participating in criminal proceedings as victims. The goal is to analyze the problems that arise in connection with the participation of foreigners in the investigation, and develop tactical and psychological and organizational and legal measures to minimize the negative impact on the investigation of problematic circumstances. Using the method of system analysis, various investigative situations were considered and the suggestions were made for organizing an investigation based on the example of questioning foreign nationals involved in criminal proceedings as victims. Conclusions: in practice, for the investigator and inquiry officer, the participation of a foreigner in the criminal process creates the need for additional organizational measures, the list of which, on the example of conducting an interrogation of the victim, is given in the paper. The effectiveness of the investigation of crimes involving foreign citizens will largely depend on the competence of the investigator in applying the provisions of the migration legislation of the Russian Federation. The conflict - free situation of interrogation of the injured foreign citizen and other investigative actions with his participation-more favorable for the investigator, as a rule, occurs only in the case of the legal status of a foreign citizen in the Russian Federation. The use of this algorithm of actions by the investigative bodies can guarantee the rights of foreign nationals involved in criminal proceedings as victims, protect their legitimate interests and conduct an effective investigation.

Key words: foreign national, criminal procedure, criminologist, techniques of interrogating a foreign national, victim, investigator, the legality of stay in the Russian Federation.

Citation. Zemskova A.I. On the Question of the Investigator's Algorithm of Actions During the Interrogation of Foreign Nationals Involved in Criminal Proceedings as Victims. Legal Concept, 2020, vol. 19, no. 3, pp. 123-127. (in Russian). DOI: https://doi.org/10.15688/lc.jvolsu.2020.3.17
\end{abstract}

\section{К ВОПРОСУ ОБ АЛГОРИТМЕ ДЕЙСТВИЙ СЛЕДОВАТЕЛЯ ПРИ ДОПРОСЕ ИНОСТРАННЫХ ГРАЖДАН, УЧАСТВУЮЩИХ В УГОЛОВНОМ ПРОЦЕССЕ В КАЧЕСТВЕ ПОТЕРПЕВШИХ}

\author{
Анна Игоревна Земскова \\ Волгоградская академия МВД России, г. Волгоград, Российская Федерация
}

Введение: в статье рассматриваются некоторые особенности тактики допроса иностранных граждан, участвующих в уголовном процессе в качестве потерпевших. Цель состоит в анализе проблем, возникающих в связи с участием иностранцев в расследовании, и выработке тактико-психологических и организационно-правовых мер по минимизации негативного влияния на ход следствия проблемных обстоятельств. С помощью 
метода системного анализа были рассмотрены различные следственные ситуации и выработаны предложения по организации расследования на примере допроса иностранных граждан, вовлеченных в уголовный процесс в качестве потерпевших. Выводы: на практике для следователя и дознавателя участие иностранца в уголовном процессе создает необходимость проведения дополнительных организационных мероприятий, перечень которых, на примере осуществления допроса потерпевшего, приведен в статье. Эффективность деятельности по расследованию преступлений с участием иностранных граждан при этом будет в значительной степени зависеть от компетентности следователя в применении положений миграционного законодательства Российской Федерации. Бесконфликтная ситуация допроса потерпевшего иностранного гражданина и других следственных действий его участием - более благоприятная для следователя, как правило, имеет место только в случае легального правового статуса иностранного гражданина в Российской Федерации. Использование органами следствия предлагаемого в статье алгоритма действий способно обеспечить гарантированность прав иностранных граждан, вовлекаемых в уголовный процесс в качестве потерпевших, защиту их законных интересов и проведение эффективного расследования.

Ключевые слова: иностранный гражданин, уголовный процесс, криминалистка, тактика допроса иностранного гражданина, потерпевший, следователь, законность пребывания в Российской Федерации.

Цитирование. Земскова А. И. К вопросу об алгоритме действий следователя при допросе иностранных граждан, участвующих в уголовном процессе в качестве потерпевших // Legal Concept = Правовая парадигма. -2020. - T. 19, № 3. - C. 123-127. - DOI: https://doi.org/10.15688/lc.jvolsu.2020.3.17

\section{Введение}

При расследовании преступлений с участием иностранных граждан в качестве потерпевших следователь неизбежно будет сталкиваться с рядом определенных особенностей, которые будут в значительной степени влиять на проведение отдельных следственных действий и на обеспечение прав и законных интересов иностранных граждан, вовлекаемых в уголовный процесс. Предметом исследования данной статьи являются наиболее, на наш взгляд, актуальные из них:

1. Непонимание иностранным гражданином требований российского законодательства ввиду значительной разницы между правовыми системами РФ и страны исхода иностранца.

2. Отсутствие в уголовно-процессуальном законодательстве Российской Федерации обязанности предоставлять иностранному гражданину, участвующему в уголовном процессе в качестве потерпевшего, государственную защиту и юридическую поддержку, в том числе со стороны иностранного государства (консульских учреждений и дипломатических представительств).

3. Языковой барьер.

4. Законность пребывания (проживания) на территории Российской Федерации иностранного гражданина, вовлекаемого в уголовный процесс в качестве потерпевшего.

\section{Некоторые аспекты тактики допроса иностранного гражданина, вовлекаемого в уголовный процесс в качестве потерпевшего}

Для минимизации негативного влияния на ход следствия перечисленных особенностей рассмотрим краткий перечень тактико-психологических и организационно-правовых мероприятий, рекомендуемых при проведении допроса потерпевшего, так как «нельзя представить себе расследование, которое можно провести без допроса - свидетелей или потерпевшего, подозреваемого или обвиняемого, а чаще всего и тех и других. Допрос неотъемлемое, обязательное следственное действие при расследовании любых преступлений» [1, с. 93].

Первый комплекс предлагаемых мер связан с юридическим разночтением норм законодательства России и иностранного государства и отсутствием у потерпевшего возможности воспользоваться услугами адвоката. Особенно данная проблема актуальна при расследовании сложных составов экономических преступлений, мошеннических действий, жертвами которых стали иностранцы. Ввиду того, что положения налогового и иного законодательства Российской Федерации могут значительно отличаться от законодательной базы, применяемой в стране гражданской принадлежности потерпевшего, у следователя при 
его допросе могут возникнуть сложности с установлением истины. В силу указанных объективных причин иностранный гражданин не может оценить действия других лиц (в том числе подозреваемых, обвиняемых) и сообщить в ходе допроса юридически значимую информацию, своевременно представить те или иные документы, фото- и видеоматериалы, которые могут помочь следователю в установлении вины или виновных лиц и, соответственно, будут способствовать восстановлению нарушенных прав и законных интересов потерпевшего иностранного гражданина.

В связи с этим задача следствия в ходе допроса получить именно ту информацию, которая предположительно известна потерпевшему, но не может быть им оценена с точки зрения ее значения для расследования уголовного дела ввиду различия правовых систем и отсутствия юридической помощи.

Для этого следователю необходимо:

1. Изучить личность иностранного гражданина с целью определения степени его юридической грамотности, может ли он дать правовую оценку произошедших с ним событий, обладает ли специальными знаниями (навыками) в конкретной сфере деятельности, непосредственно связанной с предметом расследования.

2. Проанализировать особенности законодательства государства гражданской принадлежности потерпевшего (определенной отрасли) и сопоставить с требованиями нормативных правовых документов Российской Федерации.

3. Для установления психологического контакта целесообразно иметь общее представление о принятом в государстве постоянного проживания потерпевшего этикете общения, порядке обращения, ценностных ориентирах, традициях.

4. Ввиду отсутствия адвоката частично взять на себя его функции и дополнительно разъяснять потерпевшему те или иные требования российского законодательства, особенности проведения следственных действий с целью обеспечения прав и законных интересов иностранного гражданина.

5. В рамках сотрудничества с национальными общественными объединениями и организациями (диаспорами) привлекать их членов (руководителей) для оказания юридической помощи потерпевшему иностранному гражданину, не имеющему возможности воспользоваться услугами адвоката. Под диаспорой можно понимать часть народа (этноса), проживающую вне страны своего происхождения, образующую сплоченные и устойчивые этнические группы в стране проживания и имеющую социальные институты для поддержания и развития своей идентичности и общности [4, с. 754$]$.

6. Использовать в качестве тактического приема предъявление в ходе допроса документов или предметов (фотоизображения предметов) с целью получения по ним необходимых пояснений потерпевшего и дополнительных сведений, особенно если названия этих предметов и документов требуют наличия специальных знаний (например, бухгалтерские документы).

7. По окончании допроса целесообразно уточнить полученные от потерпевшего сведения с выходом на место происшествия или путем реконструкции обстановки совершения преступления.

Приведенные меры будут способствовать также преодолению такой проблемы, неизбежно возникающей при участии иностранных граждан в уголовном процессе, как языковой барьер.

Иностранный гражданин может вообще не владеть языком, на котором ведется судопроизводство, или владеть им в объеме, недостаточном для понимания хода расследования. Так, например, выходцы из стран СНГ, как правило, владеют русским языком и в установленном порядке подтверждают, что им понятен язык судопроизводства, но при использовании в ходе допроса или иных следственных действий юридических терминов, профессиональных формулировок у них могут возникнуть трудности в понимании озвученной информации. В связи с этим при допросе потерпевшего следователю необходимо:

1. Перед непосредственным допросом потерпевшего иностранца в протоколе необходимо отразить, каким языком и/или диалектом владеет иностранный гражданин, на каком языке желает давать показания, понятен ли ему перевод лица, привлекаемого в качестве переводчика. 


\section{ПРОЦЕССУАЛЬНОЕ ПРАВО: ВОПРОСЫ ТЕОРИИ И ПРАВОПРИМЕНЕНИЯ}

2. При привлечении переводчика необходимо выяснить владеет ли он конкретным диалектом, на котором изъясняется потерпевший (например, в Исламской Республике Афганистан насчитывается более 20 языков и 200 различных диалектов).

3. Перечень предполагаемых вопросов к потерпевшему необходимо заблаговременно передавать переводчику для подготовки к допросу и более точному переводу.

4. Планируемые для предъявления в ходе допроса документы также необходимо заранее предоставить переводчику для организации их перевода.

5. В ходе допроса необходимо использовать простые речевые обороты, употребляемые слова по возможности не должны иметь несколько значений, формулировка вопросов не может допускать толкований (независимо от того, участвует переводчик или нет).

6. Фиксировать допрос с помощью технических средств (видео- и аудиозаписи) с целью получения возможности последующего воспроизведения для уточнения переводчиком полученных показаний потерпевшего. При этом от видеозаписи допустимо отказаться, если иностранный гражданин испытывает в связи с этим психологический дискомфорт и указывает на это.

\section{Законность пребывания (проживания) в Российской Федерации \\ как криминалистически значимая информация при организации расследования преступлений \\ с участием иностранных граждан}

Наконец, такая характеристика правового статуса иностранца, как законность (незаконность) пребывания в России, может оказать следующее негативное влияние на достижение целей расследования.

Бесконфликтная ситуация допроса потерпевшего, более благоприятная для следователя, как правило, имеет место только в случае легального правового статуса иностранного гражданина в Российской Федерации. Если иностранец находится на территории нашей страны в нарушение требований миграционного законодательства, то допрос будет проходить в условиях ситуации конфликта, так как нелегалы не доверяют представителям власти и, являясь нарушителями, стараются не разглашать те или иные сведения.

Таким образом, в рамках планирования следственных действий с участием иностранного гражданина органу дознания в первую очередь необходимо установить законность нахождения потерпевшего в России.

С этой целью должно быть организовано оперативное взаимодействие следователя с подразделениями МВД России по вопросам миграции или доступ органов следствия к Центральному банку данных по учету иностранных граждан. Согласно постановлению Правительства Российской Федерации от 14.02.2007 № 94, им является государственная информационная система миграционного учета (ГИСМУ). Последняя содержит «досье» на каждого иностранного гражданина, въезжающего в Российскую Федерацию, с указанием сведений о его правовом статусе, нарушениях российского законодательства, датах въезда и выезда из России и так далее [3, с. 93].

Так как должностное лицо, которое проводит расследование, помимо достижения интересов следствия должно способствовать скорейшему выдворению (депортации) нелегала за пределы Российской Федерации, то необходимым условием успешного расследования будет особая оперативность и быстрота $[2$, с. $13-15]$.

В связи с этим еще одной эффективной мерой при расследовании уголовных дел с участием иностранных граждан является необходимость создания следственно-оперативной группы с четким распределением общего объема работы между следователями и оперативными службами правоохранительных органов.

\section{Выводы}

Решение обозначенных проблем, с которыми неизбежно сталкивается следователь при участии иностранных граждан в уголовном процессе, возможно при проведении в ходе расследования комплекса предложенных в статье тактико-психологических и организационно-правовых мероприятий (на примере допроса потерпевшего).

Кроме того, с учетом отсутствия в уголовно-процессуальном законодательстве 
Российской Федерации обязанности предоставлять иностранному гражданину, участвующему в уголовном процессе в качестве потерпевшего, государственную защиту и юридическую поддержку, в том числе со стороны иностранного государства (консульских учреждений и дипломатических представительств), считаем целесообразным нормативно закрепить право потерпевшего, являющегося иностранным гражданином, на государственную и юридическую поддержку (право на предоставление адвоката).

\section{СПИСОК ЛИТЕРАТУРЫ}

1. Баев, О. Я. Тактика следственных действий : учеб. пособие / О. Я. Баев. - Воронеж : НПО «Модэк», $1995 .-224 \mathrm{c}$.

2. Бастрыкин, А. И. Расследование по делам с участием иностранных граждан / А. И. Бастрыкин, О. И. Александрова // Законность. - 2004. - № 1. C. $13-15$.

3. Земскова, А. И. К вопросу об особенностях участия иностранных граждан в уголовном процессе Российской Федерации в качестве свидетелей и по- терпевших / А. И. Земскова // Вестник Волгоградской академии МВД России. - 2017. - № 3. - С. 90-95.

4. Социология : энцикл. / сост. А. А. Грицанов [и др.]. - Минск : Книжный дом, 2003. - 1312 с.

\section{REFERENCES}

1. Baev O.Ya. Taktika sledstvennykh deystviy [Tactics of Investigative Actions]. Voronezh, NPO “Modek" Publ., 1995. 224 p.

2. Bastrykin A.I., Aleksandrova O.I. Rassledovanie po delam s uchastiem inostrannykh grazhdan [Investigation of Cases Involving Foreign Citizens]. Zakonnost [Legality], 2004, no. 1, pp. 13-15.

3. Zemskova A.I. K voprosu ob osobennostyakh uchastiya inostrannykh grazhdan $\mathrm{v}$ ugolovnom protsesse Rossiyskoy Federatsii v kachestve svideteley i poterpevshikh [To the Question About the Participation of Foreign Citizens in the Criminal Process of the Russian Federation as Witnesses and Victims]. Vestnik Volgogradskoy akademii MVD Rossii [Bulletin of Volgograd Academy of the Ministry of Internal Affairs of Russia], 2017, no. 3, pp. 90-95.

4. Gritsanov A.A., Abushenko V.L., Evel'kin G.M., Sokolova G.N., Tereshhenko O.V., eds. Sotsiologiya: entsikl. [Sociology: Encyclopedia]. Minsk, Knizhnyy Dom Publ., 2003. 1312 p.

\section{Information About the Author}

Anna I. Zemskova, Junior Scientific Assistant, Postgraduate Department, Deputy Chief of the Faculty of Foreign Specialist Training, Volgograd Academy of the Ministry of Internal Affairs of the Russian Federation, Istoricheskaya St, 130, 400089 Volgograd, Russian Federation, nunufar.07.zema@yandex.ru, https://orcid.org/0000-0003-0265-705X

\section{Информация об авторе}

Анна Игоревна Земскова, адъюнкт адъюнктуры, заместитель начальника факультета подготовки иностранных специалистов, Волгоградская академия МВД России, ул. Историческая, 130, 400089 г. Волгоград, Российская Федерация, nunufar.07.zema@yandex.ru, https://orcid.org/0000-0003-0265-705X 